\section{Seasick: Ocean Change and the Extinction of Life on Earth}

\author{
By Alanna Mitchell, University of Chicago \\ Press, 2009, 176 pages, ISBN 978-0-22653- \\ 258-5, Hardcover, $\$ 25.00$ US.
}

\section{REVIEWED BY KIHO KIM}

You feel light-headed, your knees are weak, your eyes lose focus, and whatever is in your stomach wants to get out. This sickness is familiar to many who sail on the ocean, one that I have gotten to know too well as a marine biologist. In her book Seasick, Alana Mitchell concludes that the ocean, too, is sick: light-headed from hypoxia, weak from bleaching, and upset from pollution.

Seasick is a travelog of sorts in which Mitchell takes her readers around the world to investigate the signs and causes of an unhealthy ocean. With 135 pages of text, the book is not so much a full examination but rather a "reading of the vitals," as suggested by the chapter titles. The book begins with a trip to the Great Barrier Reef "to see how the ocean should work," followed by chapters on what happens when things go awry. The range of topics is eclectic but seamlessly woven into a compelling and highly readable story about what climate change and ocean acidification (the other $\mathrm{CO}_{2}$ problem) portend for the ocean, and indeed our own survival.

A real strength of the book is Mitchell's knack for creating a sense of place and character. When in a new location, she avoids the customary geography lesson and instead uses it as an integral part of the storytelling. For example, to understand how plankton will respond to a high- $\mathrm{CO}_{2}$ world, she travels to Plymouth Marine Laboratory in England, where, she is told, the future ocean will be very different than it is now. Mitchell reminds us that Plymouth Harbor is no stranger to history-altering events-it was here the Pilgrims and later Charles Darwin began their journeys.

Mitchell is also good at giving substance to the people in her stories, scientists for the most part. On a cruise to study "the blob," a dead zone in the Gulf of Mexico, Mitchell introduces us to Stu Ludsin, who is serving as a chief scientist for the first time. She writes that Ludsin had recently competed in a triathlon in New York City that included "swimming the crazily polluted Hudson River, and he's still talking about the sludge he had to extract from his ears and nose." She goes on to reveal that Ludsin had set up a stationary bike in his stateroom so as not to "lose his training edge," only to spend much of the cruise dealing with foul weather, broken equipment, research surprises (not the good kind), and, to top it off, a bad cook.

At its core, the book is about science, and Mitchell does a splendid job explaining it. The first chapter contains a semester's worth of introductory marine ecology in only a few pages of clear, nontechnical writing. Indeed, Mitchell's storytelling style is worth emulating, especially by those who engage in teaching and science outreach. As someone who has spent some time studying coral reproduction, I was particularly taken by Mitchell's description of the end of a coral spawning event: "Suddenly, though, there's lethargy. As if the reef is having a leisurely smoke at the end of it all." This is exactly as I remember it.

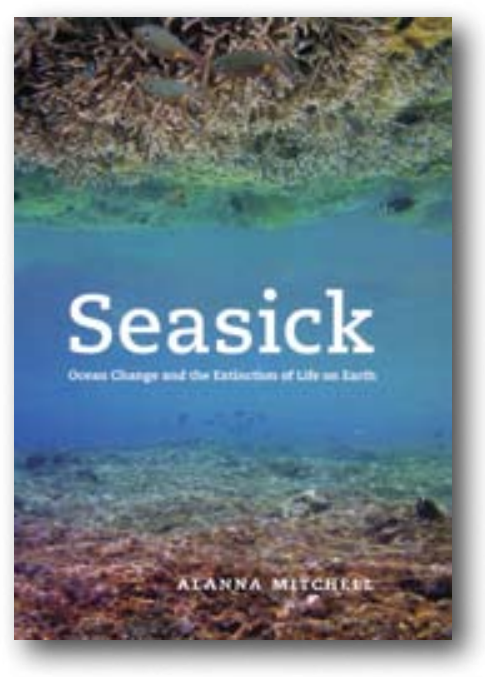

The book does have some aspects that may be considered shortcomings. Foremost, it seems odd that there is little or no mention of polar seas, given the dramatic changes that are likely to happen there. While I like the personal style of writing, it does come at the expense of appearing to lack scientific rigor. Facts are presented without citing sources, although there is a select bibliography, and there was little I saw in error other than not mentioning the role of thermal expansion as a cause of sea-level rise.

The ocean is undergoing rapid and fundamental change, sure signs of sickness. However, Mitchell argues, the disease is curable and the prescription is clear. What remains unsettled is whether we are willing to take our medicine. For many of us, the stories told in this book will not be new. But those stories are told with a fresh voice and are well worth listening to again, if only to remind ourselves to ask and be able to answer the question, “So what?" 正

Kiho Kim (kiho@american.edu ) is Chair, Department of Environmental Science, American University, Washington, DC, USA. 